\title{
The search for common factors in psychotherapy: Two theoretical models with different empirical implications
}

\author{
Lars-Gunnar Lundh \\ Department of Psychology, Lund University, Lund, Sweden
}

\section{Email address:}

Lars-Gunnar.Lundh@psy.lu.se

\section{To cite this article:}

Lars-Gunnar Lundh. The Search for Common Factors in Psychotherapy: Two Theoretical Models with Different Empirical Implications. Psychology and Behavioral Sciences. Vol. 3, No. 5, 2014, pp. 131-150. doi: 10.11648/j.pbs.20140305.11

\begin{abstract}
The difficulties of demonstrating that any specific form of psychotherapy is more effective than any other has led to the formulation of the so-called Dodo Bird Verdict (that all forms of therapy are equally effective) and to the suggestion that what really matters for therapeutic efficiency are factors that are common to different forms of therapy. The term "common factors", however, is seldom defined in an unambiguous way. In this paper, two different models of "common factors" are differentiated, and their implications are compared. The first model is referred to as the Relational-Procedural Persuasion (RPP) model and is primarily based on the writings of Frank and Wampold; according to this model effective psychotherapy requires a good therapeutic relationship, a specified therapeutic procedure, and a rhetorically skilful psychotherapist who persuades the client of a new explanation that provides new perspectives and meanings in life. The contents of these procedures and perspectives, however, are less important - according to this model, the treatment procedures are beneficial to the client because of the meaning attributed to these procedures rather than because of the specific nature of the procedures. The other model, the Methodological Principles and Skills (MPS) model, is based on the assumption that effective psychotherapy relies on common methodological principles that are instantiated in various ways in different forms of psychotherapy, and on the therapist's capacity of applying these principles in a skillful way. According to this model, method matters, and it is possible to improve existing methods. Whereas the MPS model carries a hope for the improvement of psychotherapy, the RPP model implies a more pessimistic view of psychotherapy as forever bound by the limits of the Dodo Bird Verdict. It is concluded that psychotherapy research may benefit from using the MPS model as a working hypothesis, but that a comprehensive model of common factors in psychotherapy also needs to integrate important insights from the RPP model, as well as an understanding of the structural characteristics that psychotherapy shares with other kinds of social interaction.
\end{abstract}

Keywords: Common Factors, Psychotherapy, Therapeutic Alliance, Placebo Effects, Dodo Bird Verdict

\section{Introduction}

Research on psychotherapy has shown a tremendous growth during the last decades. Evidence that various forms of psychotherapy really work has been obtained through a large number of randomized controlled trials (RCTs). As summarized by one of the leading researchers and methodologists in the field, however, "after decades of psychotherapy research we cannot provide an evidence-based explanation for how or why even our most well-studied interventions produce change" (Kazdin, 2009, p. 426). That is, although we know that various therapies work, we still know very little about why they work. Similarly, although there is considerably more evidence for some forms of psychotherapy (e.g., various forms of cognitive-behavior therapy) than for others (e.g., psychodynamic therapy) - mainly because much more research has been carried out on the former kinds of treatment - there is very little evidence that any form of psychotherapy is more effective than any other (e.g., Wampold, 2001). Evidence of differential efficacy requires comparative RCT studies, where one treatment is shown to be consistently more effective than another; although a large number of therapies have been shown to be more effective than control groups, however, there is still no strong evidence than any of these therapies is more effective than any other.

The difficulties of demonstrating that any specific form of psychotherapy is more effective than any other has led to the conclusion that all active psychotherapies are equally effective, the so-called Dodo Bird Verdict (e.g., Luborsky et al., 2002; Wampold, 2001), and to the suggestion that what really 
matters in psychotherapy are "common factors", or "non-specific" factors as distinct from the specific factors that are explicitly formulated in various theories of psychotherapy (Rosenzweig, 1936; Frank \& Frank, 1991). The term "common factors", however, is seldom defined in an unambiguous way, and is used in different ways by different writers, to the detriment of a genuine and fruitful discussion, and as a hindrance to the development of a more theoretically sophisticated research on how to improve the practice of psychotherapy. There is therefore a need to clarify the concept of common factors in psychotherapy.

The common factors hypothesis was first formulated by Rosenzweig (1936), who also coined the term "Dodo Bird Verdict" as a label for the hypothesis that all forms of psychotherapy work equally well. This hypothesis was later systematized into a comprehensive perspective on psychotherapy by Frank (1961; Frank \& Frank, 1991). The probably most well-known proponent for this view in present-day psychotherapy research is Wampold $(2001,2007)$ Common to these writers is that they question the assumption that the effects of psychotherapy are due to the specific methods that are used in various forms of psychotherapy. According to Frank and Frank (1991), psychotherapy is not an applied behavioral science, but rather "a form of rhetoric best studied hermeneutically" (p. 53); and Wampold explicitly rejects what he refers to as "the medical model of psychotherapy", defined as the assumption that the efficacy of psychotherapy is due to specific methods for the treatment of specific problems. Instead, Frank and Wampold emphasize the importance of common factors like the quality of the therapeutic alliance, the creation of hope, and new perspectives on one's problems.

However, the literature on psychotherapy also contains another kind of common factors thinking, which is based on the assumption that method does really matter, and that there may be important methodological commonalities between very different forms of psychotherapy which may explain their effects. Goldfried (1980), for example, argues that although different forms of psychotherapy may differ widely in terms of theory and specific techniques, they may share fundamental "therapeutic change principles", like the facilitation of new corrective experiences and the provision of direct feedback to enhance the client's awareness. Foa and Kozak (1986) have likewise argued that exposure and emotional processing represents a methodological principle that is common to a wide variety of therapies. Along the same lines, Castonguay (2000) suggests a model for training psychotherapists in the use of common factors, based on the implementation of such "general principles of change".

The present paper starts from the assumption that psychotherapy research may benefit from an increased use of hypothetico-deductive thinking not only at the "micro level" of individual empirical studies, but also at the "macro level" of theoretical models. More specifically, this means that psychotherapy research would benefit from (1) a clarification and differentiation of theoretical models of what makes psychotherapy work, (2) deducing and comparing the implications of these models, and (3) a comparison of these implications with the empirical evidence, and a generation of new ideas about how to formulate these implications into empirically testable hypotheses. The purpose of this paper is (1) to elaborate on the above-mentioned two types of thinking about common factors in psychotherapy and to formulate them explicitly into two contrasting theoretical models, and (2) to deduce and compare some of their implications.

The remaining part of the present paper consists of four main sections, and a short final section with concluding remarks. In the next section, the first of these two models is described under the label of the Relational-Procedural Persuasion (RPP) model; this is done by means of an analysis of the writings of the three main proponents of this kind of thinking: Saul Rosenzweig, Jerome Frank, and Bruce Wampold. In the section after that, the other model is described and illustrated with examples under the label of the Methodological Principles and Skills (MPS) model. In a third section the implications of these two models are compared, and in a fourth section the possibility of developing a comprehensive model of common factors is discussed. Finally, some conclusions are drawn.

\section{The Relational-Procedural-Persuasion (RPP) Model}

The term Relational-Procedural Persuasion model (or, for short, the RPP model) is used here as a label for a model of common factors in psychotherapy which emphasizes three core components: (1) the need for a good therapeutic relationship, but not as a goal in itself, but (2) as a means for engaging the client in a certain therapeutic procedure and (3) to persuade the client of a new explanation that gives new perspectives and new meanings in life. In this model, there is a basic need for a specific method or procedure, but not because of the efficiency of this procedure as such, but as a means for providing new "success experiences" in terms of the corresponding new explanation or perspective. There is also a need for a persuasive therapist who is able to provide $a$ credible rationale to make the client accept the new explanation and undergo the corresponding procedure. As can be seen from the description above, these three components are not logically independent, but are conceptually interwoven.

Importantly, this model emphasizes the form of the treatment (i.e., the presence of a procedure and a persuasive explanation, that are provided by a therapist which engages in a working relationship with the client) as what accounts for the effects, largely independently of its contents. That is, the precise nature of the therapeutic procedures used, and the contents of the new perspectives that are provided by the therapist, are not assumed to have any effect in themselves.

The present section will delineate the RPP model in more detail, by an analysis of the writings of some its main proponents. First, its origin is traced to a short paper by Rosenzweig (1936). Then, the full model is seen to be 
developed in the writings of Frank and Frank (1991), although still mixed up with some thinking concerning methodological factors. And finally, the model is given its most pure expression in the writings of Wampold $(2001,2007)$. Although none of these writers uses the designation Relational-Procedural Persuasion (RPP) for their model (Wampold refers to his model as "the contextual model"), the reason for using this terminology is that it may facilitate discussion by referring explicitly to the core elements of the model.

\subsection{Common Factors According to Rosenzweig}

Rosenzweig (1936) was probably the first writer to formulate the concept of "common factors" and the so-called Dodo Bird Verdict - the hypothesis that all psychological treatment methods are equally effective. It should be noted that this was before psychotherapy had seen anything like the proliferation of different schools that we are witnessing today. Rosenzweig, however, also included religious conversions into his comparisons. Basically, Rosenzweig questioned (1) whether the factors alleged to be operating in a given therapy are identical with the factors that actually are operating and (2) whether the factors that actually are operating in several different therapies may not have much more in common than have the factors that are alleged to be operating.

Rosenzweig suggested a number of potential "common factors", including (1) unverbalized processes in the therapeutic relationship that lead to a "social reconditioning", (2) catharsis, (3) stimulating and inspiring aspects of the therapist's personality, and (4) the "formal consistency" with which the therapist "adheres in his treatment to a system of concepts" which in one way or another has bearing on the client's psychological problems. Whereas the two former may be seen as hypothetical methodological principles (MPS factors), the two latter clearly are of the RPP kind.

The common factor which is most emphasized in Rosenzweig's paper is the fourth one - that is, his reference to "the formal consistency" with which the therapist applies certain concepts. This is also the common factor which Rosenzweig most clearly describes as being shared not only by various forms of psychotherapy, but also by a number of other procedures: "Whether the therapist talks in terms of psychoanalysis or Christian Science is from this point of view relatively unimportant as compared with the formal consistency with which the doctrine employed is adhered to, for by virtue of this consistency the patient receives a schema for achieving some sort and degree of personality organization." (Rosenzweig, 1936, p. 414).

This exemplifies a recurring theme in discussions on psychotherapy, as seen for example in Frank's (1961) comparison of modern psychotherapy to primitive forms of healing and religious conversions, and in Kilbourne and Richardson's (1984) suggestion that religious conversions may be functionally equivalent to psychotherapy.

\subsection{Common Factors According to Frank}

The title of Jerome Frank's (1961; Frank \& Frank, 1991) main work, Persuasion and healing, captures exceedingly well the two main aspects of his model: the wide definition of psychotherapy in terms of all forms of healing, and the central role attributed to persuasion and rhetoric in the healing process. The present discussion builds on the third edition of this book, which he wrote together with his daughter (Frank \& Frank, 1991).

According to Frank's definition (Frank \& Frank, 1991, p. 2), psychotherapy is a special form of personal influence characterized by (1) a healing agent, typically a person trained in a socially sanctioned method of healing believed to be effective by the sufferer and by at least some members of his or her social group; (2) a sufferer who seeks relief from the healer; and (3) a healing relationship, that is, a circumscribed, more or less structured series of contacts between the healer and the sufferer.

It is important to note that this wide definition means that the category of "psychotherapy" in Frank's model also includes methods of primitive healing, religious conversion, and even placebo effects in medicine. What all these procedures share, according to Frank and Frank (1991), is an emotionally charged, confiding relationship with a socially sanctioned helper, who may be able to instill new hope and expectations for change, and who offers new perspectives on the client's problems and life situation, in a way that may counteract the client's demoralization (anxiety, depression, low self-esteem, meaninglessness, hopelessness, etc.), and provides a method or procedure that affords the client new "success experiences".

Although the conceptual perspectives offered by different forms of psychotherapy may vary widely, the important thing, according to this model, is not their content, but their function as a $m y t h$ that provides a plausible explanation for the client's problems and may help him or her to construct new meaning in life. Similarly, although each kind of psychotherapy requires the client to pass through some kinds of technical procedures, the important thing is not their content, but their function as a ritual that provides the client with new "success experiences". By means of a good therapeutic alliance and credible rationales and procedures, psychotherapy may help clients feel and function better "by encouraging modifications in their assumptive worlds, thereby transforming the meanings of experiences to more favorable ones" (Frank \& Frank, 1991, p. 30).

According to this model, psychotherapy is not seen as an applied behavioral science but "as a form of rhetoric best studied hermeneutically" (Frank \& Frank, 1991, p. 53). Frank refers to Aristotle's model of the rhetorician as seeking to influence hearers by (a) evincing a personal "ethos" that will win the confidence of the listener; (b) engaging the listener's emotions; and (c) providing a "truth", real or apparent, by argument. Psychotherapists, just like rhetoricians are assumed to gain their power to influence others through their ethos, both in the form of personal charisma and an "ability to sense and respond to the mood of the audience" (p. 66), and in the form of "contextual reinforcers" like "diplomas and certificates attesting to membership in an established 
profession" (p. 67). Among their common features are that they all "hold out the hope that the activities they recommend will lead to enduring improvement in personal well-being" (p. 68 ), and that they rely both on the stimulation of emotions and on conceptual argument "as methods for transforming meanings" (p. 68).

Although this model denies that the treatment methods as such have an effect, and maintains that different methods may be equally effective to the degree that therapist and client believe in the methods used, the importance of therapeutic skills enters in another way. As seen from the description above, the process clearly is assumed to involve skills of influencing, and even "indoctrinating" others as efficiently as possible, in the work of the psychotherapist as well as that of the rhetorician: "Both seek to indoctrinate their listeners into their assumptive worlds. This is an overt goal of all rhetoricians and many psychotherapists, though for some of the latter, indoctrination may be subtle and indirect" (Frank \& Frank, 1991, p. 70). At the same time, it also involves skills of listening and adapting the therapist's behavior to the client. As stated by the Franks, the process requires a lot of sensitive listening on the part of the healer, since an efficient "transformation of meanings" is a collaborative process that requires "mutual understanding of the significance of the experiences the patient reports" (p. 70-71). The psychotherapist is assumed to "collaborate with the patient to construct a new plot..., preferably one that sustains a better self-image" (p. 72). The relative contributions of therapist and patient to this enterprise are assumed to vary between different forms of therapy, depending "both on how 'directive' the school of the therapist is and on the intelligence and sophistication of the patient" (p. 72).

The "common factors" referred to in this model include principles and skills concerning how to influence people as efficiently as possible - principles that are possibly used implicitly by helpers and rhetoricians in all human cultures, and are subject to explicit study in social psychological research on attitude change, persuasion, and social cognition in general. The role of training is also clearly implied by Frank and Frank (1991) when "healing ability" is likened to musical talent: "No amount of training can make a tone-deaf person into a musician. Given a modicum of musical talent and sufficient determination, however, anyone can become a passable performer, though not a virtuoso. The same may hold true for psychotherapeutic talent. Thus, while some healers may need little training, many persons can learn to be better therapists through formal study." (Frank \& Frank, 1991, p. 167)

Among the common factors that make psychotherapy work, according to Frank and Frank, are skills in (1) how to influence a client to believe in a given perspective ("myth") on psychological problems and how these may be solved, (2) how to motivate a client to undergo the procedures ("ritual") prescribed by this conceptual perspective; and in (3) how to build a good therapeutic alliance by being both directive and empathically sensitive. Frank and Frank (1991) discuss a number of ways in which these factors may interact. In the light of present-day discussions about the role of the therapeutic alliance, it is interesting to note that in their model the use of the given therapeutic methods (the "myths" and "rituals" which characterize the given form of psychotherapy) is assumed to have a causal influence on the development of the therapeutic alliance. As they write, "the adherence of therapist and patient to the same therapeutic myth creates a powerful bond between them" (p. 44); and "the ritual further serves to maintain the patient-therapist bond, especially over stretches where nothing much seems to happen" (p. 44). Expectations are described as an important mediator here: "By inspiring expectations of help, myths and rituals keep the patient coming to treatment" (p. 44); and these expectations are linked "to specific processes of therapy as well as to outcome" (p. 45). Techniques, in the form of a role-induction interview, are also described for the purpose of shaping the patient's expectations to accord with the therapeutic model (p. 150-152).

These factors represent the core of the RPP model. But Frank and Frank's (1991) thinking does not represent any pure RPP model. It is interesting to note that they also refer to methodological principles of another kind when they state that the therapy may provide the client with new learning experiences, both in the form of "cognitive learning" and "experiential learning". The latter is seen as the most important: "The more numerous and more intense the experiential, as opposed to the purely cognitive, components of learning, the more likely they are to produce changes in the patient's attitudes and behavior" (p. 46). Of central importance for the therapeutic learning to occur is also that the therapist provides "opportunities for practice", or more specifically: "opportunities and incentives for internalizing and reinforcing therapeutic gains through repeated testing both within and outside the therapeutic session" (p. 50).

In addition, Frank and Frank (1991) formulate a methodological hypothesis of the central importance of emotional arousal. Emotional arousal is said to be essential to therapeutic change in several ways, as for example (a) by supplying the patient with the necessary "motive power" to undergo the therapeutic process; (b) by facilitating attitudinal change and enhancing sensitivity to environmental influences; and (c) by breaking up old patterns of personality organization and facilitating the achievement of better ones (p. 46). Here they criticize Western psychotherapies for not making full methodological use of this factor, considering it as "a by-product of their procedures rather than a primary focus" ( $p$. 47). Whether this hypothesis is correct or not, it represents one of several examples of hypothetical methodological principles of the MPS kind that are formulated by Frank and Frank.

That is, Frank and Frank's (1991) common factors model is a mix of RPP and MPS factors. RPP factors are heavily emphasized when they describe theories as "myths" and methods as "rituals" that have their effect by being believed in, and also when they point to the importance of rhetoric abilities, abilities to motivate the patient, and abilities to develop and maintain a therapeutic alliance in this context. In addition, however, Frank and Frank clearly go beyond the RPP model 
when they invoke methods for facilitating experiential learning and increased self-efficacy, and when they argue for the importance of inducing emotional arousal in the client to optimize these forms of learning.

\subsection{Common Factors According to Wampold}

Wampold (2001) builds on the hypotheses formulated by Rosenzweig and Frank, but also differs from them in several respects. Terminologically, he prefers to label his model "the contextual model." Also, he does not subscribe to Frank's wide culture-anthropological definition of psychotherapy as including primitive forms of healing, religious conversion and placebo effects, but explicitly restricts the term "psychotherapy" to "interpersonal treatments based on psychological principles" (Wampold, 2001, p. 3). He also introduces the term bona fide psychotherapies (Wampold, Mondin, Moody, Stich, Benson, \& Ahn, 1997) as a label for all treatments that are delivered by trained therapists and are based on psychological principles, and offered to the psychotherapy community as viable treatments through professional books or manuals. At the same time, he excludes all "alternative therapies, which are credible to the participants in the study but are not intended to be therapeutic" (Wampold et al., 1997, p. 205) from his definition of bona fide psychotherapies.

Still, Wampold admits that the mechanisms by which psychotherapy works may be shared by other procedures: "Treatments based on the occult, indigenous people's cultural beliefs about mental health and behavior, New Age ideas (e.g., herbal remedies), and religion may be efficacious through the mechanisms hypothesized in the contextual model, but they are not psychotherapy" (p. 3). That is, what makes therapy work, according to Wampold's model - just like Rosenzweig's and Frank's models - are not specific to psychotherapy. The difference between Wampold and Frank in this regard, therefore, seems to be more terminological than substantial.

A more substantial difference is that Wampold is less inclined than Rosenzweig and Frank to leave room for the possibility that "common factors" may take the form of methodological principles of the MPS kind. Such a hypothesis, according to Wampold, would remain within what he refers to as "the medical model" of psychotherapy, in contrast to his "contextual model". According to Wampold (2001), "the treatment procedures are beneficial to the client because of the meaning attributed to those procedures rather than because of their specific psychological effects" (p. 27). That is, what makes therapy work according to his model is not to be found in characteristics of the treatment methods as such, but in the explanatory system surrounding them, which the client acquires from the therapist. "The essential aspect of psychotherapy", as Wampold (2007, p. 862) puts it, "is that a new, more adaptive explanation is acquired by the patient. The means of acquisition of this new explanation is the verbal interaction between therapist and patient." This acquisition of a new explanation creates an expectation that if the treatment is followed, the difficulties experienced by the patient may be resolved. Again, it is important to note that, according to
Wampold's model, "the truth of the explanation is unimportant to the outcome of psychotherapy. The power of the treatment rests on the patient accepting the explanation rather than whether the explanation is 'scientifically' correct" (p. 863).

A basic therapeutic skill in this model, therefore, is to guide the patient to accept the therapist's explanatory model, and here the same principles are assumed to apply as in the case of religious conversions: "It appears that concepts, such as religious concepts, are best acquired when they are discrepant from currently held beliefs but do not violate an excessive number of a person's assumptions... I hypothesize that effective explanations in psychotherapy must be different from presently held explanations for a patient's troubles but not sufficiently discrepant from the patient's intuitive notions of mental functioning to be rejected." (Wampold, 2007, p. 864)

Thus, to be successful, the therapist needs to be sensitive to the patient's beliefs and assumptions concerning mental functioning (his/her "folk psychology"), and adapt the verbal interaction to optimize the patient's susceptibility to these new explanations. A therapeutic relationship characterized by empathy and warmth is important for this purpose, since it increases the patient's susceptibility to influence: "If the patient feels understood and ascertains that the therapist will work diligently in his or her behalf, then the probabilities of accepting the explanation of psychotherapy and the concomitant treatment is increased" (p. 864). Warmth and empathic listening in itself, however, is insufficient; and without providing the patient with a new explanation this is not even considered by Wampold to be psychotherapy: "a relationship with a warm therapist who responds empathically is not psychotherapy" (p. 863). This contrasts sharply with Rogers $(1951,1957)$ client-centered therapy, which (1) aspires to be non-directive (and thus does not aspire to influence the client to acquire a new explanatory system), and (2) is based on the assumption that warmth, empathy and unconditional positive regard are not only necessary but also sufficient conditions for therapeutic change.

In this context it is interesting to note that Wampold (2001) thinks of Rogerian therapy as more akin to the medical model than to his own contextual model. As he states it, Rogers's approach to therapy "fits the description of a theoretical approach subsumed under the medical model in many ways. It contains a clear theory of the person and therapeutic change as well as techniques for facilitating such change." (p. 27) Rogers' theory, in fact, can be seen as a theory about methodological principles of the MPS kind (i.e., empathy, warmth, congruence, and unconditional positive regard), that are supposed to make therapy work, and Wampold's model has little room for such methodological principles.

At the same time, it might be argued that Wampold stretches his concept of "the medical model" a bit too far by claiming that as soon as we speak about methods we are thereby using a "medical model". Are all treatment methods by definition medical? And why should it a priori be assumed that psychological theory and research cannot lead to the derivation of treatment methods that are efficient as methods 
(independently of the belief in them)?

This particular characteristic of Wampold's model also becomes salient in a comparison with the various forms of technical eclecticism that have been proposed by Lazarus (1981) and others. Although Wampold, like proponents of technical eclecticism, assumes that different clients may benefit from different therapeutic approaches, and that therapeutic methods should therefore be optimally matched to clients, he makes it clear that this is for a completely different reason. As pointed out by Wampold (2001, p. 21-22), Lazarus and other proponents of eclecticism focus on the differential effects of techniques and thereby stay within the confines of a "medical model of psychotherapy". Although Wampold also holds that therapeutic approaches should be matched with clients, this is not because of their assumed effects (as various forms of therapy are not assumed to have any differential effects), but because they may be more or less credible for different clients, and make more or less sense to them. Clients, therefore, "should select a therapy that accords with their worldview" (p. 226). In several passages he also quotes Frank and Frank's (1991, p. xv) formulations that "ideally therapists should select for each patient the therapy that accords, or can be brought to accord, with the patient's personal characteristics and view of the problem", and that "therapists should seek to learn as many approaches as they find congenial and convincing. Creating a good therapeutic match may involve both educating the patient about the therapist's conceptual scheme and, if necessary, modifying the scheme to take into account the concepts the patients bring to therapy." (Frank \& Frank, 1991, p. xv).

To summarize, Wampold adheres to Frank's assumption that techniques are necessary constituents of all efficient forms of psychotherapy - not because they have any effects as techniques, but because they supply the treatment with credible rituals. Whether the techniques are cognitive, behavioral, interpersonal or psychodynamic does not matter the important thing is that the choice of technique matches the client's beliefs and preferences. However, whereas Frank and Frank's (1991) “common factors" include several examples of MPS principles (e.g., providing opportunities for practice, new learning experiences, and arousing the clients' emotions to facilitate change), Wampold makes little mention of such factors. Wampold's model, therefore, is a much closer approximation to a pure RPP model than Frank's is.

\section{The Methodological Principles and Skills (MPS) Model}

The term Methodological Principles and Skills (MPS) model is used here as a label for a perspective on psychotherapy that is based on the assumptions (a) that effective psychotherapy relies on methodological principles which may be manifested in various forms in different kinds of psychotherapy, and (b) that successful psychotherapists are characterized by their skills in applying these methodological principles to a variety of clinical situations. Such methodological principles are found under different names, and in various versions, in many different forms of psychotherapy, and may be assumed to be more or less important with different clients. However, whereas the RPP model has been formulated quite clearly and in considerable detail by writers like Frank and Wampold who have devoted entire books to the description of this model, the same is not true of the MPS model. Illustrations of this kind of thinking are found scattered in the literature, and are probably overrepresented among writers who advocate "psychotherapy integration" in some form, although it is difficult to find any systematic description and categorization of such basic methodological principles.

An early formulation of the MPS model can be found in the writings of Goldfried (1980), who argues that different forms of psychotherapy can be compared in terms of three levels of abstraction: (1) theoretical models, (2) methodological principles, and ( 3 specific techniques. The theoretical models adopted by therapists to understand human functioning and the process of change represent the highest level of abstraction. At the lowest level are the specific techniques used to facilitate clients' improvement. According to Goldfried, very few common factors can be found either at the abstract theoretical level or at the purely technical level. Meaningful commonalities, however, are likely to be found at the intermediate level of abstraction, in the form of basic principles like the provision of a new view of self, the establishment of a working alliance, and the facilitation of corrective experiences. For Goldfried, many techniques that appear to be unique to a particular form of therapy represent, in large part, different manifestations of such common methodological principles. Elaborating further on these ideas, Castonguay (2000) argues for a "common factors approach to psychotherapy training" which focuses both on such general principles of change and their concrete instantiations as specific techniques in different forms of therapy, and the development of therapeutic skills in how to "identify specific procedures that might be more effective for particular clients" (p. 279).

From these assumptions it seems to follow that (1) there may be a number of basic methodological principles; (2) these methodological principles may be manifested in a number of widely different specific techniques; and (3) these methodological principles and their concrete manifestations may be combined in a more or less skillful way by individual therapists. If this is true, it seems that an important task for psychotherapy research would be to identify as many such basic principles as possible, and explore their various specific manifestations, and how they can be combined as efficiently as possible in various contexts.

A number of suggestions have been made of what may constitute such potentially important methodological principles that are common to different forms of psychotherapy. The following section does not attempt to present anything like a comprehensive, or even representative, sample of such methodological principles. The aim is merely to describe three examples of common methodological principles that have their 
origin in three different therapeutic orientations: (1) providing the client with new interpersonal learning experiences (with its origin in psychodynamic therapy); (2) the exposure principle (with a cognitive-behavioral origin); and (3) an empathic-validating stance (with its main origin in humanistic-experiential therapy). Examples are also given of how each such principle is manifested in the writings of therapists from all three orientations

\subsection{New Interpersonal Learning Experiences}

One type of methodological principle that has been suggested by a wide variety of writers on psychotherapy is to provide the client with new interpersonal learning experiences as part of the therapeutic relationship. This was mentioned as a possible common factor already by Rosenzweig (1936), who referred to "unverbalized processes in the therapeutic relationship" that lead to a "social reconditioning". But above all, this theme was given a central role by Franz Alexander (1946) when he suggested that the psychodynamic therapist should use the therapeutic relationship to afford the patient "corrective emotional experiences". The concept of "corrective experiences" has recently been systematically addressed and discussed in a separate volume by representatives of wide variety of psychotherapies, including psychodynamic therapy (Sharpless \& Barber, 2012), relational psychotherapy (Christian, Safran, \& Muran, 2012), cognitive-behavioral therapy (Goldfried, 2012; Hayes, Beck, \& Yasinski, 2012), and humanistic-experiential therapies (Farber, Bohart, \& Stiles, 2012; Greenberg \& Elliot, 2012).

At the most basic level, one variety of such new interpersonal experiences may occur as a natural effect of the therapeutic situation. That is, to the extent that the client is not used to being listened to in an attentive and non-critical way by others, and the therapist provides the client with the experience of being listened to in this way, this will constitute a new interpersonal experience. This kind of benevolent response from the therapist may, in turn, increase the likelihood that the client will continue to talk openly, and thereby disclose shameful, embarrassing or otherwise anxiety-related material during sessions - which may facilitate the therapeutic process.

Alexander (1946), however, took the idea much further than this. Against traditional psychoanalysis, he argued that insight was not primary; what was needed was "a new outcome" that was opposite to the client's expectations, as these had been formed by interactions with significant others in the past. In psychoanalytical terms, this was seen as "reexperiencing the unsettled old conflict but with a new ending" (Alexander, 1946, p. 67). To provide the client with such corrective experiences, Alexander suggested that the therapist's behavior should be adjusted to each particular client, in search for the kind of response that would most likely facilitate a corrective experience for that specific client. Alexander saw insight as secondary to the corrective emotional experience.

A similar methodological principle is given a central role in some varieties of behavioral and cognitive therapies, as for example Functional-Analytic Psychotherapy (FAP:
Kohlenberg \& Tsai, 1991), with its purpose of developing "intense and curative therapeutic relationships" where the contingencies of reinforcement in the therapeutic relationship are arranged to bring about new interpersonal experiences that can produce therapeutic change. Two other examples from the CBT tradition are schema-focused therapy (Young, Klosko, \& Weishaar, 2003), which involves using the therapeutic relationship as a form of "limited reparenting", and Cognitive Behavioral Analysis System of Psychotherapy (CBASP) where James McCulllough (2000, 2006) speaks of the therapist's use of "disciplined personal involvement" in the treatment of chronic depression.

Among modern psychodynamic therapists, the importance of a special kind of corrective emotional experiences has been stressed by Kohut (1984) and Safran and Muran (2006): the interpersonal experience of reestablishing, or repairing, a therapeutic relationship that has been temporarily disturbed. As argued by Kohut (1984), there are no perfect therapists. All therapists will now and then fail in their empathic understanding of the patient's experiences, and thereby produce less appropriate interpretations or responses that cause a weakening of the empathic bond between patient and therapists. If such empathic failures and their effects on the therapeutic relationship are attended to by the therapist, however, and dealt with in a non-defensive explorative manner, the empathic bond may be reestablished. Further, as argued by Kohut, such a process may even serve to strengthen the therapist-client relationship and provide the client with a new benign interpersonal experience that contributes to therapeutic change.

Similar processes of "repairing ruptures in the therapeutic alliance" are given a prominent role in the writings of Safran and Muran (2006), who define a rupture in the therapeutic alliance as a tension or breakdown in the collaborative relationship between patient and therapist. Such ruptures may take a number of different forms, from relatively minor tensions which therapist and/or client are only vaguely aware of, to major breakdowns in collaboration, understanding, or communication, which lead either to withdrawal or aggressive responses from the client. If the therapist is able to maintain a curious and non-defensive stance in this kind of situation, the working alliance may be repaired, and the client may learn that it is safe to express negative feelings without destroying the relationship.

In person-centered therapy and other varieties of humanistic-experiential therapy, new interpersonal experiences also have a central role, although they are not primarily conceptualized as "corrective" experiences, but rather as "experiences that lead to change or growth" (Farber et al., 2012). For example, by responding to clients with an unconditional positive regard, prizing clients as they are, listening to them in an open-minded manner, showing warmth, and being genuine, the person-centered therapist is assumed to provide clients with new interpersonal experiences that make them more able to listen closely to themselves, and accept various parts of themselves in a way that may promote personal growth. 
To summarize, we have here a potential methodological principle (or possibly a category of similar principles, which are united by certain family resemblances) which spans over a large number of therapeutic approaches. The implication is not that these various writers are referring to exactly the same kind of methodological processes, but that their various suggestions may all be categorized under the label of providing the client with new interpersonal learning experiences.

This, however, also raises the question under what conditions such interpersonal learning experiences serve therapeutic goals, and under what conditions they don't. It is also important to bear in mind the possibility that iatrogenic effects may occur in this context, if a therapist is not sufficiently skilled to handle interpersonal situations with the client in an optimal way. A number of therapeutic skills may be required if the therapist is to be able to provide the client with occasions for new interpersonal learning experiences in an efficient way. For example, the therapist has to be able to conceptualize the client's problem appropriately (to infer which kinds of interpersonal interactions might be therapeutic and which may be counter-therapeutic), and to have an adequate empathic understanding of the client's experiences so that the interventions can be individually adapted and well-timed.

\subsection{The Exposure Principle}

Another example of a methodological principle that is manifested in various ways in different forms of psychotherapy is the principle of gradual exposure, defined as a set of therapeutic strategies designed to help the patient, little by little, to substitute approach for avoidance of anxiety-related stimuli. Although this principle has its origin in cognitive-behavioral approaches to the treatment of anxiety disorders, it has also been discussed within a number of other treatment orientations and treatment contexts. As argued by Foa and Kozak (1986), "a common principle for the treatment of neuroses has emerged across schools of psychotherapy: the principle of exposure. Indeed, if neurotics are avoiders who fail to recognize and/or retrieve discomfort-evoking information about themselves or their environment, psychotherapy might be construed as providing a setting in which confrontation with such information is promoted so that changes in affect can occur." (Foa \& Kozak, 1986, p. 20).

The principle of exposure is basic to the CBT treatment of phobias, panic disorder, obsessive-compulsive syndrome (OCD), and post-traumatic syndrome (PTSD). Although the nature of the anxiety-related stimulus may differ - external situations (in phobias), body sensations (in panic disorder), thoughts (in OCD), and memories (in PTSD) - the methodological principle is basically the same: First, therapist and patient collaborate to establish an anxiety hierarchy, so that patients can start their exposure with relatively less anxiety-inducing stimuli, and gradually move on with more anxiety-related ones as the "easier" ones are managed). Second, the therapist has to be able to motivate the patient not only to approach the anxiety-related stimuli but also to abstain from using safety behaviors for the purpose of anxiety reduction (which is sometimes referred to as "response prevention").

In the psychodynamic tradition, Wachtel (1977) argued that psychoanalytic interpretations serve to expose the patient to internal manifestations of anxiety (memories, impulses, emotions, etc.), and that this tends to be done in a gradual manner (as in CBT), as a function of the patient's readiness for these interpretations. The most explicit use of the exposure principles in psychodynamic therapy, however, is probably represented by Leigh McCullough's Affect Phobia Therapy (e.g., McCullough \& Andrews, 2001), which is a short-term psychodynamic therapy that conceptualizes internal conflicts as "affect phobias". That is, the basic idea is that internal conflicts involve a fear of affects and an avoidance of these. Stepwise exposure to feelings, in combination with the prevention of defensive responses, is accordingly hypothesized to be the fundamental agent of therapeutic change.

Within the humanistic-experiential tradition, the exposure principle is perhaps most clearly manifested in Perls' (1973) Gestalt therapy, where the therapist uses a variety of techniques (awareness exercises, imagery, two-chair techniques, etc.) to bring the client into "the here-and-now" and to encourage the client to "stay with the feeling", rather than avoiding it.

There is so far no consensus concerning the theoretical explanation of why exposure works. The research literature, however, provides a number of possible hypotheses. For example, research in social psychology by Zajonc (1968) and others have established a so-called "mere exposure effect", meaning that repeated unreinforced, and brief exposure to a stimulus leads to an increased positive affect in response to that stimulus.

Although this might suggest that exposure could have effects independently of its context, other theories suggest that context is essential. According to Wolpe's (1958) theory of reciprocal inhibition, for example, exposure to anxiety-related stimuli works to the extent that it occurs in a context characterized by anxiety-reducing elements. This can also be described as an incompatibility principle. The classical example (in Wolpe's original model) is to train the patient in relaxation, and then induce the patient to approach the feared stimulus (either in the imagination or in vivo) in a relaxed state. Because anxiety is assumed to be incompatible with relaxation, this is assumed to lead to a relearning so that anxiety is no longer equally associated with the previously feared stimulus. According to this incompatibility principle, however, other aspects of the therapeutic situation that are incompatible with anxiety may have a similar effect. Some examples would be a safe therapeutic relationship characterized by trust and secure attachment (e.g., Fosha, 2003), experiences of mindfulness or acceptance, and positive memories/images.

The incompatibility principle is also central to Foa \& Kozak's (1986) theory of emotional processing. According to this theory, anxiety disorders are due to fear structures (memory structures) within the individual, and therapy works 
by modifying these fear structures. Two conditions are required to reduce the pathological fear: First, the fear structure must be activated; this is done by means of exposure to anxiety-related material. And second, new information incompatible with the pathological elements of the fear structure must be incorporated into it. Such new anxiety-incompatible information is provided, for example, (a) when the client stays in the situation for a sufficiently long time to experience that the feared outcome did not occur (changed outcome expectations), and (b) when the client perceived that he/she is in fact able to manage the anxiety-evoking situation by approaching it rather than avoiding it.

An efficient use of the exposure principle probably requires a number of other therapeutic skills, including the ability to conceptualize the client's problems appropriately (to be clear about what the client should be exposed to, and in what dosage), to explain the rationale for the treatment in such a way that the client understands it and is motivated to undergo the treatment, and to tune in empathically to the client's experiences so that the interventions can be individually adapted and well-timed. In the absence of such therapeutic skills, a "mechanistic" use of exposure may be ineffective, and even dangerous.

It should be noted that the two potential methodological principles that have been mentioned so far are not completely conceptually independent. In fact, there is a partial conceptual overlap between the exposure principle and the interpersonal learning principle, at least when the anxiety refers to interpersonal situations. That is, some interpersonal learning experiences may have the form of substituting approach for avoidance (e.g., the development of self-assertion in a client with avoidant personality disorder).

\subsection{Empathic Listening and Validation}

A third example of a methodological principle that has been given central importance by various writers within many forms of psychotherapy is what may be referred to as empathic listening and validation of the client's experiences. This principle was first systematically formulated by Rogers (1957) in his hypothesis that empathy, warmth, genuineness, and unconditional positive regard are not only necessary but also sufficient conditions for psychotherapy to work. Within the psychoanalytic tradition, Kohut (1984) has similarly emphasized the importance of empathic observation and empathic response, and within cognitive-therapy a strong emphasis on empathy and validation is seen in Linehan's (1993, 1997) writings.

Basically, the use of empathic listening and validation of the patient's experiences may be important to facilitate the development of a therapeutic alliance (e.g., Hougaard, 1994). But it may also have other kinds of effects (e.g., Kohut, 1984), like internalizing an image of an empathic other (i.e., the therapist), that may continue to be available as a source of support and understanding also in the therapist's absence, and also to an internalization into the self of a kind of "self-empathic attitude". According to Linehan (1997), validation may have a number of effects, like strengthening the therapeutic relationship, teaching clients self-validation, reinforcing clinical progress, and teaching clients a non-judgmental way of thinking about themselves.

Although empathic listening and validation need not require any more elaborate skills with clients who suffer from less severe problems, it may require a considerable methodological sensitivity and sophistication with patients who have difficulties trusting others, or who have other forms of severe interpersonal difficulties. Although this may well be a general principle that applies to all forms of psychotherapy, therefore, it nevertheless seems to acquire crucial importance especially in certain contexts, as for example in the treatment of highly emotionally vulnerable patients, and especially when the patient's interpersonal problems are manifested in the therapeutic relationship.

\subsection{Other Methodological Principles}

The three above-mentioned examples of hypothetical methodological principles are primarily meant as illustrations of the MPS model. These are not necessarily the most important principles of this kind, and there is no assumption made that the way they are construed above (as interpersonal learning experiences, exposure, and empathic listening and validation) is the optimal one. A large number of other hypothetical methodological principles could probably also be added - as for example, facilitating the client's awareness, depth of experiencing, mindfulness, and insight. Further, an interesting question is to what extent these different principles are conceptually independent. As seen above, the concept of corrective emotional experiences clearly shows a certain overlap both with the principle of exposure, and with an empathic-validating stance.

\section{Comparison between the RPP and MPs Models and their Implications}

To summarize, the RPP model and the MPS model represent two different forms of thinking about common factors. According to the RPP model, effective psychotherapy contains three basic common factors: (1) a good therapeutic relationship, which engages the client in (2) a certain therapeutic procedure and helps persuade the client of (3) a new explanation that provides new perspectives and new meanings in life. The therapeutic procedure, however, is not assumed to have any effect in itself, and the explanatory system need not have any scientific validity - the important thing is that the client is motivated to undergo the procedure, and can be persuaded to believe in the new explanation.

The MPS model, on the other hand, rests on the basic assumption that treatment methods are more or less effective, and that there are basic methodological principles that need to be identified if we are to develop as effective forms of psychotherapy as possible. According to the MPS model, common methodological principles of this kind are manifested in the form of different technical procedures and 
with different labels in different forms of psychotherapy.

In this section of the paper, the RPP and MPS models are compared in terms of their implications. First, two interrelated implication of the RPP model are focused: (a) that the effects of psychotherapy, according to this model, are not specific to psychotherapy as such, but are due to mechanisms that are found also in a number of other contexts, and (b) that psychotherapy cannot be expected to be more effective than "alternative" forms of treatment, provided that they contain the same common RPP factors (i.e., relation, procedure, and persuasion). The MPS model, on the contrary, implies that it is possible to formulate basic methodological principles that go far beyond "alternative" forms of healing in terms of efficiency.

Second, it is argued that the RPP model, unlike the MPS model, is neutral to whether treatments are helpful or harmful in the long run. That is, the RPP model is equally applicable to a large variety of social influencing processes, including those that are detrimental to the client's well-being.

Third, it is noted that, although the RPP model denies the role of treatment methods in successful psychotherapy, it rests on an assumption that some therapeutic skills are important to be able to influence the client in the desired way (e.g., rhetorical ability, the ability to develop and maintain a good therapeutic alliance, and the ability to motivate the client to engage in the therapeutic work). The MPS model, on the other hand, emphasizes a much broader set of therapeutic skills than merely social influencing skills.

Fourth, it is argued that the MPS model carries much more optimistic implications about the future development of psychotherapy than the RPP model - which basically questions the possibility of improving the effects of psychotherapy.

Fifth and finally, it is argued that a pure RPP model is untenable, as it leads to a logical paradox.

\subsection{According to the RPP Model, What Makes Therapy Work is Not Due to Psychotherapy as Such}

Following Frank's wide definition of psychotherapy, the RPP model is not assumed to apply only to psychotherapy as such, but also to methods of primitive healing, religious conversion, and the use of placebo effects in medicine. It is important to realize that (a) if the RPP model is equally applicable to those other practices, and (b) if the RPP factors are all there is to psychotherapy, then this implies (c) that psychotherapy as such has no real effect. That is, what makes psychotherapy work, according to the pure RPP model, is shared with a number of other procedures - religious and quasi-religious procedures, placebo effects, and various kinds of alternative therapies - in such a way that it cannot be maintained that the effects are specifically due to psychotherapy.

It should be noted that the RPP factors are to be found also in medical treatment. That is, medical treatments always involve (1) a doctor-patient relationship, (2) a therapeutic procedure, and (3) a theoretical rationale for why the patient should undergo this treatment. As part of the medical treatment, the doctor (by means of his or her rhetorical skills, alliance skills, etc.) may be more or less successful in persuading the patient to engage in the treatment, and as a result the patient may develop positive expectations about the treatment and hope for a cure. Altogether, these processes are categorized as "placebo effects", and it is well documented that these processes may have a real effect on health that may sometimes be surprisingly strong, and which requires an explanation in terms of psychological and psychophysiological processes (e.g., Lundh, 1987, 1992).

In research on pharmacological treatments it is assumed that the real effects of the substance can be separated from the placebo effect by means of randomized controlled trials with a double-blind condition (i.e., so that neither doctor nor patient are aware of who is receiving the supposedly active substance and who is receiving the placebo). Because double-blind conditions cannot be used in research on psychological treatments (as it is practically impossible to keep at least the therapist blinded as to which patient is receiving psychotherapy and which is not), it is much more difficult to separate the effects of the treatment method from the placebo effects in this case. If Wampold (2001) is correct, however, this may be no problem as the methodological procedures in his model do not have any effect apart from "the meaning attributed to those procedures" (Wampold, 2001, p. 27). What Wampold (2001) does here, in fact, is analogous to reducing the effects of psychotherapy to the same kind of mechanisms that are used to explain placebo effects in medicine.

If the effects of psychotherapy really are due to processes that are not specific to psychotherapy, and similar effects may be obtained in other contexts by socially sanctioned helpers without any professional training as psychotherapists, it may be questioned whether psychotherapists really need the rather costly training that is used in Western cultures today. That is, it may be asked if the current practices of training psychotherapists are really cost-efficient. If similar effects can be obtained by socially sanctioned helpers without any formal training in psychotherapy, why should we insist that therapists must undergo long and costly training programs, based on scientific theories which merely serve as "myths" like any other kind of credible myths?

One possible reason, in terms of the RPP model, would be if it were the case that only scientifically based forms of psychotherapy are credible in a certain culture, because its "Zeitgeist" promotes a belief in science over and beyond other human practices. In view of the widespread beliefs in different forms of religion, astrology, and alternative medicine even in today's most science-oriented cultures, however, it may be doubted whether this is really the case anywhere today.

The common factors of the MPS model, on the other hand, are clearly specific to psychotherapy, and are assumed to be due to the methods used in psychotherapy. This also means that, to the extent that the MPS model of common factors in psychotherapy is correct, psychotherapy as such has a substantial effect beyond what can be accomplished by professionally untrained helpers with good RPP skills. 
Moreover, the MPS model implies that to optimize the effects of psychotherapy, therapists should undergo formal training programs that are based on scientific knowledge about basic methodological principles.

\subsection{The RPP Model, Unlike the MPS Model, is Neutral to Whether Treatments are Helpful or Harmful}

Another interesting thing about the common factors of the RPP model is that they can be generalized even beyond the healing context. Using a trusting personal relationship to persuade a person of a certain way of looking at things, and to undergo a certain procedure to strengthen these beliefs, represents a kind of process that may be used for a large variety of purposes. That is, apart from being applicable to occult forms of healing, alternative therapies and placebo effects in medicine, it may also be applied to religious and political conversions, the engagement in various cults, and, in fact, to all forms of psychological influencing processes. Along partly similar lines, Lampropoulos (2001) has argued that the common factors of psychotherapy represent basic change-inducing processes that are found in a wide variety of different social interactions, including "parenting relationships, educational relationships, religious activities, mentoring and coaching of any kind (e.g. sports, acting), medical treatment, sales, and politics" (p. 23).

Further, the RPP model may be seen as "value-neutral", in the sense that it is applicable not only to treatments that are helpful but also to treatments that are indifferent or even harmful to the client. That is, RPP skills may be used not only to help a person achieve better health and problem solution, but also to engage the person for other purposes that may not always be to the long-term benefit for him or her. An effective salesperson may, for example, use these skills to sell more of a certain kind of goods to the customer.

Even within the field of psychotherapy, this kind of procedure could be either therapeutic or iatrogenic. For example, the RPP model is equally applicable to potentially harmful psychological treatments (e.g., Lilienfeld, 2007), if these use a strong therapeutic alliance to persuade clients, for example, that their problems are based on childhood sexual abuse that are beyond conscious access and that require them to undergo various procedures to gain access to these allegedly repressed memories. That is, even on the assumption that these are false memories, and that these kinds of therapies may be harmful for those who undergo them, the treatment may well be "efficient" (at least in the short term) in the sense that it leads to significant change in the client. This means that efficiency in terms of the RPP model may be defined as change caused by the treatment, whether this change is beneficial or detrimental to the client.

The MPS model, on the other hand, is not value-neutral in this sense. Basic methodological principles of the kind that are strived for here, by definition, represent therapeutic change principles. An important consideration in the attempt to formulate basic methodological principles, in fact, is to differentiate between helpful and harmful uses of various treatment techniques like corrective experiences, exposure, interpretation, and confrontation. Efficiency in terms of the MPS model is defined in terms of improved health, personal growth, increased awareness or insight, better coping, or some other effect that is experienced as helpful for the client.

\subsection{The Role of Skills in the Two Models}

Although the RPP model denies the role of treatment methods for successful psychotherapy, it does clearly require certain skills in the therapist: rhetorical skills, listening skills, skills in developing and maintaining a good working alliance, motivational skills (being able to stimulate and inspire the client to undergo certain treatment procedures), being able to provide feedback and support during the process, etc. These may be thought of as a general kind of social influencing skills, which are important in all kinds of social influencing processes, including psychotherapy. These skills are important in persuading an individual to undergo a certain procedure and accept a certain explanatory system, and if psychotherapy is reduced to such a social influencing process then these skills are sufficient for carrying out successful psychotherapy.

The MPS model, unlike the RPP model, is based on the assumption that it is possible to develop effective treatment methods for helping clients with their psychological problems - that is, methods that have an effect in themselves whether the client believes in them or not. What characterizes the MPS model is the assumption that, underneath the wide variety of different techniques that are found within various therapeutic orientations, there are certain common methodological principles that can be distilled through theoretical analysis, and that therapists can be trained to use in a skillful way. Although no theoretical consensus has yet been arrived at concerning the nature of these fundamental methodological principles, it is important to note that these methodological principles basically are assumed to require a much broader set of clinical skills than merely social influencing skills. The change that is strived for in the MPS model is not only a change in explanatory system, but also in other areas of cognitive functioning (e.g., the development of new coping skills), in emotional functioning, and in interpersonal behavior, and this requires a broader set of skills in the therapist.

\subsection{MPS Optimism Versus RPP Pessimism}

These two models of common factors also have opposite implications with regard to the possibilities of improving the practice of psychotherapy. The RPP model implies a rather pessimistic view on psychotherapy, with little prospects for improving the practice of psychotherapy, beyond the Dodo Bird Verdict. The MPS model, on the other hand, presents a much more optimistic perspective on the possibilities of developing the effectiveness of psychotherapy. Whereas the MPS model views psychotherapy as an applied behavioral science, and thereby has a positive view on the possibilities of improving its effects as the result of scientific advances, the RPP model denies that psychotherapy is an applied behavioral science and sees psychotherapy as "a form of rhetoric best studied hermeneutically” (Frank \& Frank, 1991, p. 53). 
In terms of the RPP model, psychotherapy may vary in outcome, as a function of the presence of the various RPP factors. If all "bona fide psychotherapies", in Wampold's terms, are assumed to include these factors (a credible explanatory system and therapeutic procedure, and a good working alliance) to a similar extent, we should not expect any statistically significant differences in efficacy between various forms of psychotherapy when they are compared at the group level. To the extent that individual therapists will vary in their RPP skills (rhetorical skills, skills in developing and maintaining a working alliance, motivational skills, listening skills, etc.), however, individual therapies may still differ in outcome - and different therapists may be more effective than others. In other words, the RPP model predicts that the therapist factor may be considerably more important for outcome than the method factor. The MPS model, by its focus on the importance of the therapist's methodological skills, also predicts that the therapist factor may be highly important for outcome, but in contrast to the RPP model it also predicts that the choice of methods will matter.

Still another implication of the RPP model is that, if different therapies are differentially credible in different cultures, or in different historical periods, their effects may be expected to differ from one culture, or time, to another. For example, it is possible that psychoanalytic therapy is more credible and effective in one historical period than another. Similarly, it may be expected that the effects of cognitive-behavioral therapies will differ from one time period to another, depending on the prevalent "Zeitgeist".

Still, it is important to remember that the RPP model leaves no room for the improvement of psychotherapy by the development of new and more efficient methods. According to the RPP model, the development of psychological science has no implications for the development of psychotherapeutic techniques. In terms of the philosophy of science, Wampold's model fits better with social constructionism (i.e., psychotherapeutic change is reduced to a change in the individual's social constructions of his or her problems and their solution).

The MPS model, on the other hand, opens up for the development of more effective therapeutic techniques as the result of scientific advances. It also implies that scientific research may lead to a better theoretical understanding of existent techniques by the identification of common methodological principles, so that these may be used in a more efficient way, and be of benefit to more patients.

The MPS model differs from the RPP model most clearly by assuming that psychological research may be used to improve the methods of psychotherapy - an assumption that is explicitly denied by the RPP model. Here it may be asked what reasons there are to assume a priori, as is done in the RPP model (most clearly by Wampold, 2001), that psychological theory and research cannot lead to the derivation of treatment methods that are efficient as methods (independently of the belief in them)?

What does the empirical evidence show in this regard? Meta-analyses of psychotherapy show that a considerable number of clients fail to benefit from psychotherapy. For example, among patients who suffer from depression around $50 \%$ do not respond to treatment (e.g., Westen \& Morrison, 2001), and around $50 \%$ of those who do respond tend to relapse or develop new episodes of depression within two years if they do not receive continuation-phase treatment (Vittengl, Clark, Dunn \& Jarrett, 2007). Although the percentages improved are somewhat larger in patients with anxiety disorders, around $30-40 \%$ still fail to benefit from psychotherapy (e.g., Westen \& Morrison, 2001). This suggests that there should be considerable room for improvement of treatment methods. On the other hand, meta-analyses that compare effect sizes over time show little evidence that treatments have become more effective over time (e.g., Öst, 2008) - which is consistent with the RPP model. The treatment of post-traumatic stress syndrome (PTSD), however, seems to be a possible exception to this rule (Bradley, Greene, Russ, Dutra, \& Westen, 2005); here recently tested methods have produced larger effect sizes than earlier methods, which speaks against the RPP model at least in this case.

To summarize, this means that the RPP model has not yet been empirically falsified (although the improved results in the treatment of PTSD over the years at least represent an "anomaly" for the RPP model). But the fact that it has not yet been disproved does not mean that it has been shown to be correct.

\subsection{A Common Factors Paradox}

As shown above, Wampold's model is a much closer approximation to a pure RPP model than the Franks' or Rosenzweig's models. Whereas both Rosenzweig's (1936) and Frank and Frank's (1991) "common factors" include several examples of MPS principles (e.g., social reconditioning and catharsis in Rosenzweig's case, and providing opportunities for practice, new learning experiences, and arousing the clients' emotions to facilitate change in the Franks' model), Wampold makes little mention of such factors.

Still, however, Wampold's model clearly requires certain kinds of skills in the therapist, like rhetorical skills, listening skills, skills in developing and maintaining a good therapeutic alliance, motivational skills (being able to stimulate and inspire the client to undergo certain methodological procedures), and being able to provide feedback and support during the process. In a discussion of how to train psychotherapists, Wampold states that, in addition to acquiring expertise in the theory and techniques of particular approaches, "the emphasis in training should be placed on core therapeutic skills, including empathic listening and responding, developing a working alliance, working through one's own issues, understanding and conceptualizing interpersonal and intrapsychic dynamics, and learning to be self-reflective about one's work" (Wampold, 2001, p. 230).

Here Wampold clearly argues for a stronger emphasis on the training of certain skills. But thereby he also risks being caught in a logical paradox. Suppose, as a thought experiment, that therapists who are especially trained in such a program - 
let us call it "common factors therapy" - are compared in a clinical trial with therapists trained in some traditional therapeutic approach which does not emphasize these kinds of skills in a similar way (e.g., some form of behavior therapy). Consider two alternative potential outcomes: (1) the "common factors therapy" shows a better outcome, or (2) it shows an equivalent outcome to the comparison treatment. If it shows a better outcome, this would serve as a falsification of Wampold's model - which predicts that effects cannot be improved by therapeutic ingredients that are specific to one form of therapy (even if these specific factors are referred to as "common factors"). If it shows an equivalent outcome, on the other hand, this would corroborate the common factors model and the Dodo Bird Verdict, but at the expense of the hypothesis that the skills trained are in fact "core therapeutic skills".

Could this logical paradox be taken as a reductio ad absurdum of Wampold's version of the common factors model? In mathematics and formal logic, the term "reductio ad absurdum" refers to an argument where a contradiction is derived from some assumption, thus showing that the assumption must be false. Some kind of assumption obviously must be false here.

There seem to be two ways out of the paradox: Either it has to be admitted that the common factors referred to in Wampold's model cannot be translated into core therapeutic skills that can be taught as part of formal training programs. Or it has to be admitted that at least some of these common factors can be regarded as methodological principles (shared by some but not all forms of therapy) which can be translated into technical skills - but then it follows that method matters, and the Dodo Bird Verdict is false. And we have then shifted from a pure RPP model to a model which at least in part includes MPS factors.

\section{Towards a Comprehensive Model of Common Factors in Psychotherapy}

In the widest perspective, psychotherapy is a form of social interaction between two or more people. More specifically, it is a goal-directed form of social influencing process where one individual tries to influence another individual towards a goal (which in the case of psychotherapy may be improved health, well-being, personal development, insight, learning, or behavioral change). A comprehensive model of common factors in psychotherapy requires an analysis of what all kinds of psychotherapy have in common by being (1) a form of social interaction, and (2) a goal-directed form of social influencing process. The RPP model captures some of the structural characteristics of the latter (i.e., a relationship, a methodological procedure, and a persuasive theoretical rationale). But we also have to take into account the structural characteristics that are shared by all forms of social interaction.

This raises the following question: What are the structural characteristics that all forms of psychotherapy share by being a form of social interaction? Basically, all such structural characteristics present the psychotherapist with a challenge: how should these structural characteristics be handled by the therapist when they are manifested in the psychotherapy session? This challenge may be handled at an implicit, intuitive level (e.g., by some kind of heuristics; e.g., Kahneman, 2011), or it may be handled by means of explicitly formulated methodological principles, based in some theory about psychotherapy. In addition, these methodological principles may be more or less common to various forms of psychotherapy - and belong to the common factors that are addressed by the MPS model.

As an illustration of these questions, this section will discuss some structural characteristics and how they are handled methodologically in different forms of psychotherapy. This is done in terms of (1) the therapist's and client's actions in relation to each other, (interpersonal actions), and (2) their reactions to each other (interpersonal reactions). To illustrate what a comprehensive approach to these questions might mean, the discussion makes use of concepts from a number of different approaches to psychotherapy: learning theory, humanistic-experiential therapy, the hypnosis tradition, and psychoanalysis.

\subsection{Therapists' and Clients'Interpersonal Actions}

Therapists inevitably act in relation to their clients, and clients inevitably act in relation to their therapists. There are a number of questions that can be asked with regard to the nature of therapist action. For example, to what extent does the therapist follow a manual or protocol, and to what extent does the therapist follow more "intuitive" leads? To what extent is the therapist directive or non-directive? To what extent is the therapist's actions adapted to the client's way of responding to these actions? To what extent does the therapist act as a genuine person, and not only as a professional, in the interaction with the client? Although all forms of psychotherapy have a set of prescriptions for how the therapist should act in order to be an effective therapist, these prescriptions may be more or less stringent, and leave more or less room for non-technical action. In this section, some of these questions are briefly discussed in terms borrowed from learning theory ("contingencies of reinforcement"), humanistic-experiential therapy ("non-directivity"), and the hypnosis tradition ("suggestion").

One important aspect of the interaction between therapist and client is how the therapist acts in response to the client's behavior. Here it may be argued that all therapies inevitably have their "contingencies of reinforcement" (Skinner, 1969), in the sense that different actions from the client are met differently by the therapist in such a way that some client behaviors are strengthened whereas others are weakened. This means that differential reinforcement represents a structural characteristic of psychotherapy in general. The exact nature of those actions that are met with positive responses and those that are not (or those that are even met with negative responses from the therapist) may vary from one therapy to another - but all therapies have their specific contingencies in this regard. In 
other words, there are no neutral therapists; therapists by necessity respond differentially to various kinds of client communications. This differential way of responding has its roots partly in the theory that guides the therapist, and that provides guidelines for what kinds of client behaviors are seen as conducive to the goals of therapy. A psychoanalyst, for example, is likely to respond positively when the patient produces free associations and arrives at new insights, but not when the patient asks personal questions to the therapist. A cognitive-behavioral therapist responds positively when patients carry out exposure assignments and give the "right" kinds of answers to Socratic questions, but not when patients have forgotten to do their homework.

Although it can be assumed that all forms of therapy have their contingencies of reinforcement, this is capitalized on methodologically (i.e., in terms of explicit methodological principles) more by some forms of therapy than by others. This is seen most clearly in behavior therapists who use behavior analytic principles and so-called "contingencies management".

Person-centered therapy might perhaps be thought to be an exception to the principle of differential reinforcement of client's behavior, as it openly advocates a non-directive stance (Rogers, 1957). But also in this form of therapy some client behaviors are assumed to be more conducive than other behaviors to personal growth and self-actualization, and are thereby responded to more positively by the therapist. The contingencies of reinforcement that characterize person-centered therapy bear some similarity to what Ryan and Deci (2008) refer to as an "autonomy-supporting environment", which is assumed to facilitate self-organization and self-regulation. Such an environment inevitably contains components of differential reinforcement, whereby the therapist encourages what is perceived as clients' expressions of increased self-organization and self-regulation.

How, then, is a non-directive stance at all possible? Can a therapist really act non-directively, or is this just an illusion? Following Rogers (1951), a therapeutic intervention can be considered "nondirective" when the therapist encourages the client to reach his/her own answers, insights, solutions and decisions, out of respect for the client's autonomy and with an openness to follow the client's direction. Many kinds of therapeutic interventions can be carried out either in a directive or non-directive manner. For example, a psychodynamic interpretation may be stated either (non-directively) as a hypothesis to be considered by the client, or (directively) as a "truth" that the client is assumed to accept as an "insight". Similarly, a cognitive therapist may ask so-called "Socratic questions" (non-directively) in an open-ended manner without any preconceived notion of what the answer might be, or ask them (directively) in the form of leading questions by which the therapist wants to lead the client to certain predefined answers. Whether the therapist acts directively or non-directively in these contexts, he or she is likely to respond more positively when the client responds in accordance with the therapist's assumptions of what should be helpful to the client. That is, a non-directive stance simply represents a different set of contingencies than a directive stance.

Because psychotherapy by definition is a goal-directed activity designed to improve the well-being of the client, some degree of directivity is a common structural characteristic of psychotherapy. The exact nature of the overall goal, however, may differ between various therapies, and the methods used to approach the goal may be more or less directive in different therapies. In addition, the degree of directivity/non-directivity is not only a matter of therapeutic orientation, but also depends on the personal style of the therapist. What this implies is that, although directivity is a structural characteristic of psychotherapy, it exists in degrees, and does not exclude the possibility that therapists may take a nondirective stance. As expressed elsewhere, it rather means "that a nondirective attitude always exists in a context of directive influences. There is always room for nondirective interventions in therapy, and the nondirective attitude may be quite dominant in the work of some therapists, but even the most nondirective of therapists will also influence their clients" (Lundh, 2012, p. 231).

One kind of influence, which has not yet been mentioned but which is probably ubiquitous to all forms of social interaction, is the subtle forms of suggestion whereby one person's expression of feelings and thoughts tends to influence another to feel, or think in a similar way. This has been referred to as normal suggestion (Lundh, 1998) A classic example is so-called emotional contagion, where one person by expressing an emotion influences another person to enter the same kind of emotional state. It is possible, for example, that a psychotherapist who expresses hope and optimism in a positive emotional manner may thereby influence the client's emotional state in the same direction. In terms of modern psychological research, this kind of "normal suggestion" can be understood as a form of priming (e.g., Bargh, 2006). Normal suggestion in this sense may be intentional or unintentional on the part of the person who does the "suggesting," and generally relies on non-conscious mental processes in the recipient. In this perspective, "each social situation (including each psychotherapeutic treatment) is assumed to be characterized by a certain 'suggestive climate,' as a function of the frequency with which various ideas, intentions, feelings, etc., are primed" (Lundh, 1998, p. 24).

Suggestion may play an important role at many levels in psychotherapy. One fairly uncontroversial example is when it occurs at the motivational level. As Wachtel (1993) describes it, therapists of various orientations use suggestion either implicitly or explicitly in a wide range of ways to motivate their clients to confront the conflictual issues in their life. By means of suggestion, for example, clients can be helped temporarily to gain the confidence needed to face what they fearfully avoid, as done in various kinds of exposure treatment, or to take steps to change a troubling life pattern. Suggestion, however, is considerably more controversial when it is used at the cognitive level, for example, to induce the client to accept a certain interpretation. For example, skillful repetition of a certain interpretation will tend to increase its subsequent 
familiarity, and research shows that a statement will seem true if it expresses facts that seem familiar (e.g., Begg, Anas, \& Farinacci, 1992), which means that the repetition of a certain statement may have a definite suggestive impact. Another process that may further increase the suggestive impact is if a client visualizes certain scenes as a result of a certain interpretation; research indicates that visualizing an event tends to increase the person's confidence in the reality of this event having occurred (e.g. Intraub \& Hoffman, 1992).

At the same time, as pointed out for example by Bowers and Farvolden (1996), it is definitely not the case that clients will accept just any interpretation. Whether the client accepts an interpretation or not will depend on the degree to which it fits with his or her beliefs, thoughts, and feelings. But where do these beliefs, thoughts and feelings come from? One possibility is that they are at least partly the result of previous processes of suggestive influence. One possibility, therefore, is that there may occur processes of 'suggestive shaping', where the client's beliefs, thoughts, and feelings are changed in small, almost imperceptible steps, until the client is ready to accept the full-fledged interpretation in its entirety.

As formulated by Bowers and Farvolden (1996), it is impossible for a therapist to engage in suggestion-free psychotherapy, in the same way that it is impossible for a physicist to observe electrons without disturbing them in the process. If so, it is of paramount importance that the therapist is aware of these forms of influence; otherwise he or she will produce effects that are not well understood and may even result in adverse iatrogenic effects. Recognizing the inevitability of suggestive influences in psychotherapy will help minimize their untoward effects; whereas minimizing or denying the ubiquity of suggestion will render both therapist and patient especially vulnerable to its unintended and potentially damaging influence.

In some forms of therapy, these processes are capitalized on methodologically in a very explicit manner by the therapist. This is seen most clearly in hypnosis and in Ericksonian psychotherapy (e.g., Matthews, 2000), where there is a systematic and intentional use of these processes for therapeutic purposes. Although therapists from many other orientations have a considerably less positive attitude to suggestive forms of influencing, however, examples of explicit methodological uses of suggestion can also be found in CBT and psychodynamic therapy. In some varieties of cognitive-behavior therapy, for example, "imagery rescripting" represents an active utilization of such processes (e.g., Stopa, 2011). Also within psychoanalysis Freud (1916) admitted that there are suggestive processes at work, in the form of "positive transference", which clothes the analyst with authority and "is transformed into belief in his communications and explanations", without which "the patient would never even give a hearing to the doctor and his arguments" (p. 446). Nevertheless, the explicit methodological use of suggestion represents an exception in both CBT and psychodynamic therapy.

That is, even if normal suggestion is ubiquitous in all psychotherapy, different forms of psychotherapy may differ widely in their explicit awareness and methodological use of these processes. Here the MPS model of common factors implies that we should try to find methodological principles for harnessing these suggestive influences as efficiently as possible in the service of the client's treatment goals. The topics of suggestion, differential reinforcement and directivity/non-directivity represent structural characteristics of psychotherapy that need to be integrated in a comprehensive model of common factors in psychotherapy.

\subsection{Client's and Therapists' Interpersonal Reactions}

To shift the perspective from action to reaction, it can be assumed that clients inevitably react to their therapists, and that therapists also inevitably react to their clients. In this section, these processes will be briefly discussed, with a starting-point in the psychoanalytic concepts of "transference" and "countertransference".

It is generally acknowledged that the effects which one individual has on the other will depend at least in part on that other person's past learning history, including experiences with significant others (e.g., parents). In psychotherapy, starting with Freud (1916), this is referred to as transference. Further, in social psychological research such transference processes have been found to occur generally in social interactions (e.g., Andersen \& Berk, 1998; Andersen \& Przybylinski, 2012). In the latter kind of research, transference is defined as involving "the activation of idiosyncratic, subjective knowledge about a significant other from memory", which occurs "when a new person behaves or communicates in such a way that is (or appears) similar to a significant other", and leads to the automatic application of this knowledge "to a new person in order to interpret and respond to this person" (Andersen \& Przybylinski, 2012, p. 372).

It can be assumed that some degree of transference will occur in all forms of psychotherapy, in the sense that mental representations of significant others are triggered by cues in the situation and leads the client to view the therapist in terms of these mental representations. At the same time, the therapist's way of handling these processes is likely to differ widely between different forms of psychotherapy.

Classical psychoanalysis, for example, emphasizes the importance of the therapist's abstinence and neutrality, for the purpose of facilitating a relatively pure projection of the client's inner relational world onto the therapist, thereby making the client's inner world available for analysis, interpretations, and new insights. If Andersen and Przybylinski's (2012) conceptualization is correct, however, with its implication that transference develops "when a new person behaves or communicates in such a way that is (or appears) similar to a significant other", it follows that there is no such thing as a neutral therapist; a therapist who acts "neutral" will simply activate other aspects of mentally represented significant others than will a more empathic or supportive therapist. This also means that, to the extent that a therapist is likely to listen more empathically, show more of unconditional positive regard, approach the patient's problems with more interest, etc., than is usually the case in human 
interactions, this will activate internal representations of positive interactions with significant others from the past. The transference may then be expected to take a more positive turn than is typical of everyday interactions with others, and develop primarily into some degree of "positive transference" that will facilitate the development of a therapeutic alliance (Freud, 1913).

Most forms of cognitive-behavior therapy do not focus methodologically on the transference at all, although there are some exceptions like James McCullough's (2000) Cognitive Behavioral Analysis System of Psychotherapy (CBASP) which prescribes a specific procedure for detecting and handling transference reactions among chronically depressed patients. This, however, does not mean that transference does not take place in typical forms of CBT. Transference processes, as defined above, may be expected to occur as common structural aspects of all kinds of psychotherapy, although all therapies do not have specific methodological prescription for working with these processes. Moreover, as long as the transference is generally of a positive benign nature there is little need to focus on it.

When more complicated forms of transference are likely to develop, as in the treatment of patients with borderline personality disorder, however, even CBT approaches (like Dialectical Behavior Therapy; Linehan, 1993) have explicit methodological prescriptions for handling such processes (although these processes are not necessarily referred to in terms of "transference").

An interesting theoretical question is to what extent common methodological principles for using transference processes can be distilled from therapeutic approaches that are rooted in widely different theories. For example, what is common and what is specific about the methodological prescriptions for handling transference processes in Transference-Focused Psychotherapy (Clarkin, Yeomans, \& Kernberg, 1999), Mentalization-Based Treatment (Bateman \& Fonagy, 2004), Dialectical Behavior Therapy (Linehan, 1993), Functional-Analytic Psychotherapy (Kohlenberg \& Tsai, 1991), and Schema-Focused Psychotherapy (Young, Klosko, \& Weishaar, 2003)?

But it is not only the client who reacts to the therapist - the therapist also reacts to the client. Freud (1910) observed that the therapist may sometimes respond emotionally to the patient in a way that can interfere with the treatment, and named it countertransference. Originally, this was assumed to be due to unresolved issues in the therapist's past experiences with significant others (and thus seen as a form of therapists' transference). Later psychoanalysts and psychotherapists, however, have broadened the focus, recognizing that the therapist's reactions to the patient may, in fact, carry important information about the kind of responses which the client tends to evoke in others, and can thereby be used to facilitate the treatment. Instruments have also been developed to measure this kind of "countertransference" (e.g., Betan, Heim, Conklin, \& Westen, 2005), and empirical data suggest that patients with different forms of personality disorders tend to evoke specific kinds of reactions in others, in such a way that "clinicians, regardless of therapeutic orientation, can make diagnostic and therapeutic use of their own responses to the patient" (Betan et al., 2005, p. 890).

This, however, means that the concept of "countertransference" has shown a drift in meaning, from Freud's original conceptualization (which saw countertransference as a threat to the treatment) to modern conceptualizations (which see it as a source of information about the patient). Here it is obvious that we are, in fact, dealing with two different concepts, which need to be differentiated. One explicit attempt to such a differentiation is seen in Kiesler's distinction between objective and subjective countertransference. "Objective countertransference", in this conceptualization, refers to "the constricted feelings, attitudes, and reactions of a therapist that are evoked primarily by the client's maladaptive behavior and that are generalizable to other therapists and to other significant persons in the client's life" (Kiesler, 2001, p. 1057). "Subjective countertransference", on the other hand, refers to "the defensive and irrational reactions and feelings a therapist experiences with a particular client that represent residual effects of the therapist's own unresolved conflicts and anxieties" (Kiesler, 2001, p. 1057).

Another solution would be to keep the term "transference" to the latter phenomenon, in recognition of the fact (if we are to believe the conclusions drawn by Andersen and her co-workers on the basis of their social psychological research; Andersen \& Przybylinski, 2012) that transference processes occur in all individuals, including therapists, in their interaction with others. We would then need another term to designate forms of "objective countertransference" that may serve as a source of information about the client's interpersonal patterns.

It should, however, also be noticed that there is a partly similar problem concerning the client's transference processes in psychotherapy. Keeping to the Freud's original definition, the term "transference" should only refer to those aspects of the client's reactions to the therapist which are transferred from significant others in the client's past. However, the term "transference" is often more loosely used to refer to all of the clients's reactions to the therapist, independently of their origin (just as the meaning of the term "countertransference" has drifted to refer to all of the therapist's reactions to the client, independently of their origin).

Here a case can be made for restoring the original meaning of the term "transference", and for introducing some other term to designate those aspects of the client's reactions which occur in response to aspects of the real therapist as he or she appears in the session. Gelso (2014) makes a similar distinction by differentiating between "the real relationship" and the "transference/countertransference configuration", as two separable aspects of the interaction between therapist and client. Here he quotes Freud as implying such a distinction, for example, when he stated that "Not every good relation between an analyst and his subject during and after analysis was to be regarded as transference; there were also the friendly relations which were based on reality and which proved to be viable" (Freud, 1937, p. 222). 
To summarize, this is an area where we are in need of improved conceptualizations. Although there are some suggestions concerning conceptual developments in the literature, however, there is yet no consensus concerning the solution to these conceptual problems. For the present purposes it is sufficient to note (1) that the client's reactions to the therapist represents a challenge to be understood (either as transference, or as reaction to the therapist as a real person), and (2) that the therapist's reactions to the client also represents a challenge to be understood (either as the therapist's own transference, or as a source of information about the client's interpersonal patterns). In this regard, these processes represent structural characteristics of psychotherapy that need to be dealt with in a comprehensive model of common factors in psychotherapy.

\section{Conclusion}

This paper started from the assumption that psychotherapy research may benefit from an increased use of hypothetico-deductive thinking not only at the "micro level" of individual empirical studies, but also at the "macro level" of theoretical models. In other words, it was assumed that psychotherapy research will benefit from a clarification and differentiation of theoretical models of what makes psychotherapy work, and a deduction of, and comparison between the implications of these models. An analysis of the literature on common factors in psychotherapy led to the identification of two different theoretical models of common factors, with widely different implications: the Relational-Procedural Persuasion (RPP) model, and the Methodological Principles and Skills (MPS) model.

The RPP model contains three core components: (1) the need for a good therapeutic relationship as a means for (2) engaging the client in a certain therapeutic procedure, (3) to persuade the client of a new explanation that gives new perspectives and new meanings in life. The effects of psychotherapy are assumed to be due to the therapist's and client's belief in the therapeutic procedures, whereas the therapeutic procedures in themselves are not assumed to have any real effect.

The MPS model, on the other hand, is based on the assumption that effective psychotherapy relies on methodological principles which are manifested in different ways, and under different names, in various forms of psychotherapy. Successful psychotherapists are assumed to be skilled in applying these methodological principles to a variety of clinical situations.

Underlying these theoretical models are different philosophies of science: whereas the MPS model is based on the assumption that psychotherapy is an applied behavioral science, the RPP model does not view psychotherapy as an applied behavioral science but as a "a form of rhetoric best studied hermeneutically" (Frank \& Frank, 1991, p. 53)

The RPP model has many highly controversial implications. For example, because the effects of psychotherapy are attributed to non-methodological factors that are shared with a number of other procedures (alternative treatments, "occult" therapies, and religious conversions), the effects of psychotherapy cannot be said to be specific to psychotherapy as such, and psychotherapy cannot be expected to be more effective than "alternative" forms of treatment, provided that they contain the same common RPP factors (i.e., relation, procedure, and persuasion). This means that, if the RPP model is a sufficient model of psychotherapy, we would have to rethink the future of psychotherapy, and whether the present system for training psychotherapists is necessary.

An alternative possibility, however, is that the RPP factors may be important in psychotherapy as well as in other contexts, but are quite insufficient for the understanding of psychotherapy. Even if the RPP factors are seen as a set of "core factors of psychotherapy", there are other highly important factors involved - either common factors of the MPS kind, or more specific factors that are associated with specific forms of psychotherapy. If so, it may be asked (a) how much of the effects of present-day psychotherapy are due to the mechanisms described by the RPP model, and (b) if there are some patients for whom the RPP factors are sufficient, and in that case how large this group may be. In this context, it is relevant to note that Frank and Frank (1991) argued that their common factors are sufficient for the treatment of patients who suffer from what they called "demoralization" (which they suggested is the main problem for the majority of clients who seek psychotherapy), but that other more complex problems may need additional methods.

The empirical evidence so far cannot be said to have falsified the pure RPP model. There is still little evidence that any form of psychotherapy is more effective than any other (which should be the case if methods matter). On the other hand, because the evidence indicates that only at most 50-60\% of the patients seem to benefit from the best researched forms of psychotherapy today, there should be room for the improvement of psychotherapy. Here the MPS model carries more optimistic implications about the future development of psychotherapy than the RPP model - which basically questions the possibility of improving the effects of psychotherapy, and sees these as forever bound by the limits of the Dodo Bird Verdict.

According to the MPS model, the efficacy of psychotherapy can be improved to the extent that we are able to (1) identify basic methodological principles, (2) understand how these basic principles should be applied most efficiently to different kinds of problems and in different contexts, and (3) train therapists in the skills needed to apply these basic methodological principles in the most efficient way. We cannot be sure of the truth of this model. The possibility cannot be excluded a priori that Wampold may be right in his assumption that methods do not matter in psychotherapy, and that for some reason it would be impossible to use psychological science to develop better therapeutic methods. But psychotherapy research may still benefit from using the MPS model as a working hypothesis.

This requires both empirical and theoretical work. The theoretical complexities that are involved are probably 
underestimated in present-day research on psychotherapy. Among other things, the search for basic methodological principles may need to include the development of a taxonomy of methodological skills, as well as procedures for operationalizing and measuring such skills. In these endeavors, we should not, however, forget that the RPP model may, in fact, have identified some basic methodological principles (i.e., principles that psychotherapy share with other social influencing processes). Further, we may also need to clarify the structural characteristics that psychotherapy share with other kinds of social interaction (as seen in processes like differential reinforcement, suggestion, directivity, transference, and countertransference) and which require methodological skills to handle.

\section{References}

[1] Alexander, F. (1946) The principle of corrective emotional experience. In F. Alexander \& T. M. French (Eds.), Psychoanalytic therapy: Principles and applications. New York: Ronald Press.

[2] Andersen, S. M., \& Berk, M. (1998). Transference in everyday experience: Implications of experimental research for relevant clinical phenomena. Review of General Psychology, 2, 81-120.

[3] Andersen, S. M., \& Przybylinski, E. (2012). Experiments on transference in interpersonal relations: Implications for treatment. Psychotherapy, 49, 370-383.

[4] Bargh, J. A. (2006). What have we been priming all these years? On the development, mechanisms, and ecology of nonconscious social behaviour. European Journal of Social Psychology, 36, 147-168.

[5] Bateman, A. \& Fonagy, P. (2004). Psychotherapy of Borderline Personality Disorder: mentalization based treatment. Oxford: Oxford University Press.

[6] Begg, I. M., Anas, A. and Farinacci, S. (1992). Dissociation of processes in belief: Source of recollection, statement familiarity, and the illusion of truth. Journal of Experimental Psychology: General, 121, 446-458.

[7] Betan, E., Heim, A. K., Conklin, C. Z., \& Westen, D. (2005). Countertransference phenomena and personality pathology in clinical practice: An empirical investigation. American Journal of Psychiatry, 162, 890-898.

[8] Bowers, K. S. and Farvolden, P. (1996). Revisiting a century-old Freudian slip - From suggestion disavowed to the truth repressed. Psychological Bulletin, 119, 355-380.

[9] Bradley, R., Greene, J., Russ, E., Dutra, L., \& Westen, D. (2005). A multidimensional meta-analysis of psychotherapy for PTSD. American Journal of Psychiatry, 162, 214-227.

[10] Castonguay, L. G. (2000). A common factors approach to psychotherapy training. Journal of Psychotherapy Integration, $10,263-282$.

[11] Christian, C., Safran, J. D., \& Muran, C. (2012). The corrective emotional experience: A relational perspective and critique. In L. G. Castonguay \& C. E. Hill (Eds.), Transformation in psychotherapy: Corrective experiences across cognitive behavioral, humanistic, and psychodynamic approaches (pp. 51-68). Washington, DC, US: American Psychological Association.
[12] Clarkin, J. F., Yeomans, F. E., \& Kernberg, O. F. (1999). Psychotherapy for Borderline Personality. New York, NY: John Wiley \& Sons.

[13] Farber, B. A., Bohart, A. C., \& Stiles, W. B. (2012). Corrective (emotional) experiences in person-centered therapy: Carl Rogers and Gloria Redux. In L. G. Castonguay \& C. E. Hill (Eds.), Transformation in psychotherapy: Corrective experiences across cognitive behavioral, humanistic, and psychodynamic approaches (pp. 103-120). Washington, DC, US: American Psychological Association.

[14] Foa, E. B., \& Kozak, M. J. (1986). Emotional processing of fear: Exposure to corrective information. Psychological Bulletin, 99, 20-35.

[15] Fosha, D. (2000). The transforming power of affect: A model for accelerated change. New York: Basic Books.

[16] Frank, J. D. (1961). Persuasion and healing: A comparative study of psychotherapy. Oxford, England: Johns Hopkins University Press.

[17] Frank, J. D., \& Frank, J. A. (1991). Persuasion and healing: A comparative study of psychotherapy. (Third edition.) Baltimore, MD: Johns Hopkins University Press.

[18] Freud, S. (1913). On beginning the treatment (Further recommendations on the technique of psycho-analysis I). In: J. Strachey (Ed), Standard Edition of the Complete Psychological Works of Sigmund Freud (Vol. 12, p. 123-144).

[19] Freud, S. (1916). Introductory lectures to psycho-analysis. In: J. Strachey (Ed), Standard Edition of the Complete Psychological Works of Sigmund Freud, Vol. 15-16. London: Hogarth Press, 1955.

[20] Freud, S. (1937). Analysis terminable and interminable. In J. Strachey (Ed.), Standard edition of the complete works of Sigmund Freud (Vol. 23, pp. 216-253). London: Hogarth Press.

[21] Gelso, C. J. (2014). A tripartite model of the therapeutic relationship: Theory, research and practice. Psychotherapy Research, 24, 117-131.

[22] Goldfried, M. R. (1980). Toward the delineation of therapeutic change principles. American Psychologist, 25, 991-999.

[23] Goldfried, M. R. (2012). The corrective experience: A core principle for therapeutic change. In L. G. Castonguay \& C. E. Hill (Eds.), Transformation in psychotherapy: Corrective experiences across cognitive behavioral, humanistic, and psychodynamic approaches (pp. 13-30). Washington, DC, US: American Psychological Association.

[24] Greenberg, L. S., \& Elliot, R. S. (2012). Corrective experiences from a humanistic-experiential perspective. In L. G. Castonguay \& C. E. Hill (Eds.), Transformation in psychotherapy: Corrective experiences across cognitive behavioral, humanistic, and psychodynamic approaches (pp. 85-102). Washington, DC, US: American Psychological Association.

[25] Hayes, A. M., Beck, J. G., \& Yasinski, C. (2012). A cognitive behavioral perspective on corrective experiences. In L. G. Castonguay \& C. E. Hill (Eds.), Transformation in psychotherapy: Corrective experiences across cognitive behavioral, humanistic, and psychodynamic approaches (pp. 69-84). Washington, DC, US: American Psychological Association. 
[26] Hougaard, E. (1994). The therapeutic alliance: a conceptual analysis. Scandinavian Journal of Psychology, 35, 67-85.

[27] Intraub, H. and Hoffman, J. E. (1992). Reading and visual memory: Remembering scenes that were never seen. American Journal of Psychology, 105, 101-114.

[28] Kahneman, D.. A. (2011). Thinking, fast and slow. New York: Macmillan.

[29] Kazdin, A.E. (2009). Understanding how and why psychotherapy leads to change. Psychotherapy Research, 19, $418-428$

[30] Kiesler, D. J. (2001). Therapist countertransference: In search of common themes and empirical referents. Journal of Clinical Psychology/In Session: Psychotherapy in Practice, 57, 1053-1063.

[31] Kilbourne, B., \& Richardson, J.T. (1984). Psychotherapy and new religions in a pluralistic society. American Psychologist, 39, 237-251.

[32] Kohlenberg, R. J., \& Tsai, M. (1991). Functional analytic psychotherapy. New York: Plenum.

[33] Kohut, H. (1984). How does analysis cure? Chicago: University of Chicago Press.

[34] Lampropoulos, G. K. (2001). Common processes of change in psychotherapy and seven other social interactions. British Journal of Guidance and Counselling, 29, 21-33.

[35] Lazarus, A. A. (1981). The practice of multimodal therapy. New York: McGraw-Hill.

[36] Lilienfeld, S. O. (2007). Psychological treatments that cause harm. Perspectives on Psychological Science, 2, 53-70.

[37] Linehan, M.M. (1993). Cognitive.behavioral treatment of borderline personality disorder. New York: Guilford Press.

[38] Linehan, M. M. (1997). Validation and psychotherapy. In A. C. Bohart \& L. S. Greenberg (Eds.). Empathy reconsidered. New directions in psychotherapy. Washington, DC: American Psychological Association.

[39] Luborsky L., Rosenthal R., Diguer L., Andrusyna T.P., Berman J.S., Levitt J.T., Seligman D.A. \& Krause E.D., The Dodo bird verdict is alive and well - mostly. Clinical Psychology: Science and Practice, 2002, 9, 2-12.

[40] Lundh, L. G. (1987). Placebo, belief, and health. A cognitive-emotional model. Scandinavian Journal of Psychology, 28, 128-143.

[41] Lundh, L.G. (1992). Placebo, cognition, and emotion. In W. Bongartz (Ed.) Hypnosis: 175 years after Mesmer. Recent developments in theory and application. Konstanz: Universitätsverlag, p. 151-159.

[42] Lundh, L. G. (1998). Normal suggestion. An analysis of the phenomenon and its role in psychotherapy. Clinical Psychology and Psychotherapy, 5, 24-38.

[43] Lundh, L. G. (2012). Non-directivity as a therapeutic stance, and dimension of therapeutic relating. Person-Centered \& Experiential Psychotherapies, 11, 3, 225-239.

[44] Matthews, W. J. (2000). Ericksonian approaches to hypnosis and therapy: Where are we now? International Journal of Clinical and Experimental Hypnosis, 48, 418-426.
[45] McCullough, Jr, J. P. (2000). Treatment for chronic depression Cognitive Behavioral Analysis System of Psychotherapy. New York: Guilford Press.

[46] McCullough, Jr, J. P. (2006). Treating chronic depression with disciplined personal involvement: CBASP. Richmond, VA: Springer.

[47] McCullough, L., \& Andrews, S. (2001). Assimilative integration: Short-term dynamic psychotherapy for treating affect phobias. Clinical Psychology: Science and Practice, 8, 82-97.

[48] Öst, L. G. (2008). Cognitive-behavior therapy for anxiety disorders: 40 years of progress. Nordic Journal of Psychiatry, 62, Suppl 47, 5-10.

[49] Perls, F. S. (1973). The Gestalt approach \& Eyewitness to therapy. Palo Alto, CA: Science and Behavior Books.

[50] Rogers, C.R. (1951). Client-centered therapy. Its current practice, implications, and theory. Boston: Houghton Mifflin.

[51] Rogers, C. R. (1957). The necessary and sufficient conditions of therapeutic personality change. Journal of Consulting Psychology, 21, 95-103.

[52] Rosenzweig, S. (1936). Some implicit common factors in diverse methods in psychotherapy. American Journal of Orthopsychiatry, 6, 412-415.

[53] Ryan, R.M., \& Deci, E.L. (2008). A self-determination approach to psychotherapy: The motivational basis for effective change. Canadian Psychology, 49, 186-193.

[54] Safran, J. D., \& Muran, J. C. (2006). Has the concept of the alliance outlived its usefulness? Psychotherapy, 43, 286-291.

[55] Sandler, J. (1976) Countertransference and role-responsiveness. International Review of Psychoanalysis, 3, 43-47

[56] Sharpless, B. A., \& Barber, J. P. (2012). Corrective emotional experiences from a psychodynamic perspective. In L. G. Castonguay \& C. E. Hill (Eds.), Transformation in psychotherapy: Corrective experiences across cognitive behavioral, humanistic, and psychodynamic approaches (pp. 31-50). Washington, DC, US: American Psychological Association.

[57] Skinner, B. F. (1969). Contingencies of reinforcement. New York: Appleton-Century-Crofts.

[58] Stopa, L. (2011). Imagery rescripting across disorders: A practical guide. Cognitive and Behavioral Practice, 18, 421-423.

[59] Vittengl, J. R., Clark, L. A., Dunn, T. W., \& Jarret, R. B. (2007). Reducing relapse and recurrence in unipolar depression: A comparative meta-analysis of cognitive-behavioral therapy's effects. Journal of Consulting and Clinical Psychology, 75, 475-488.

[60] Wachtel P. (1977). Psychoanalysis and Behavior Therapy. New York: Basic Books, 1977.

[61] Wachtel, P. (1993). Therapeutic Communication. New York: Guildford Press.

[62] Wampold, B. E. (2001). The great psychotherapy debate. Models, methods, and findings. Mahwah, N.J.; Lawrence Erlbaum Associates. 
[63] Wampold, B. E. (2007). Psychotherapy: The humanistic (and effective) treatment. American Psychologist, 62, 857-873.

[64] Wampold, B. E., Mondin, G. W., Moody, M., Stich, F., Benson, K., \& Ahn, H. (1997). A meta-analysis of outcome studies comparing bona fide psychotherapies: empirically, "all must have prizes”. Psychological Bulletin, 122, 203-15.

[65] Westen, D., \& Morrison, K. (2001). A multidimensional meta-analysis of treatments for depression, panic, and generalized anxiety disorder: An empirical examination of the status of empirically supported therapies. Journal of Consulting and Clinical Psychology, 69, 875-899.

[66] Wolpe, J. (1958). Psychotherapy by reciprocal inhibition. Stanford: Stanford University Press, 1958.

[67] Young, J. E., Klosko, J. S., \& Weishaar, M. E. (2003). Schema therapy: A practitioner's guide. New York: Guilford Press.

[68] Zajonc, R. B. (1968). Attitudinal effects of mere exposure. Journal of Personality and Social Psychology, 9, 1-27. 